\title{
ENVOLVIMENTO EM ATOS INFRACIONAIS E COM DROGAS COMO POSSIBILIDADES PARA LIDAR COM O PAPEL DE FILHO PARENTAL ${ }^{1}$
}

\author{
Maria Aparecida Penso ${ }^{2}$ \\ Universidade Católica de Brasília \\ Maria Fátima Sudbrack ${ }^{3}$ \\ Universidade de Brasília
}

\begin{abstract}
Este estudo busca compreender a contribuição da dinâmica familiar no processo de construção identitária de adolescentes que cometeram atos infracionais e são usuários de drogas, vivendo em situação de pobreza e exclusão social. Seu referencial teórico é a Teoria Sistêmica. Utiliza-se da metodologia qualitativa de pesquisa-intervenção com dez adolescentes em medida sócio-educativa de semiliberdade e suas famílias. Os resultados apontam para a função do uso de drogas e do cometimento de atos infracionais na adolescência, como uma das saídas encontradas pelo adolescente para lidar com o papel de filho parental, permitindo a resolução da crise identitária.
\end{abstract}

Descritores: Família. Adolescência. Droga (uso). Crise de identidade.

1 Este artigo apresenta parte dos resultados da Tese de Doutoramento da sua primeira autora, intitulada Dinâmicas Familiares e Construções Identitárias de Adolescentes Envolvidos em Atos Infracionais e com Drogas, defendida no Instituto de Psicologia da Universidade de Brasília, em 2003, sob orientação da segunda autora.

2 Universidade Católica de Brasília, QS 07, Lote 01, Águas Claras, Taguatinga, DF. CEP 71966-700. Endereço eletrônico: penso@ucb.br

3 Universidade de Brasília, Brasília, DF. CEP 70910-900. Endereço eletrônico: fatsudbr@unb.br 
— ste artigo tem com objetivo discutir a contribuição das relações familiausuários de drogas, na construção da sua identidade. Para isto discute conceitos como construção identitária, adolescência, relações familiares, uso de drogas, envolvimento em atos infracionais e parentalização, a partir da Teoria Sistêmica. Sendo parte dos resultados de uma tese de doutorado, descreve uma das metáforas usadas para definir o lugar do filho na dinâmica familiar, intitulada "O filho parental". A idéia defe ndida é que o filho, neste lugar de parentalização, lança mão do uso de drogas e envolve-se em contextos de infração como forma de lidar com esta situação.

\section{Construção identitária, adolescência e relações familiares}

Para a Teoria Sistêmica, a identidade é uma construção prioritariamente familiar, em que a família é compreendida como a "matriz de identidade", envolvendo os processos de separação e pertencimento ao longo do Ciclo de Vida Familiar e da história transgeracional (Bowen, 1976, 1991; Fishman, 1996; Minuchin, 1982; Minuchin \& Fishman, 1990; Rosset, 2003).

O processo de pertencimento e separação, fundamental para a construção identitária e no qual a família esteve engajada desde a sua constituição, provoca, na adolescência, um questionamento maior, em função da expansão das relações do adolescente, e uma crise na família, que afeta e gera mudanças em todos os seus membros (Ausloos, 1982a, 1983; Colle, 2001; Cuendet, 1991; Fishman, 1996; Miermont et al., 1994; VieytesSchmitt, 1991).

Compreendida como fase do Ciclo de Vida Familiar, a adolescência possui algumas tarefas específicas, envolvendo todos os membros da família, já que o crescimento dos filhos pressupõe a evolução dos pais frente a essa nova realidade (Carter \& McGoldrick, 1995). São importantes neste momento a flexibilidade e permeabilidade das fronteiras familiares, a flexibilidade de papéis, a negociação e uma nova modulação da autoridade pa- 
rental (Preto, 1989/1995; Carter \& McGoldrick, 1989/1995; Minuchin \& Fishman, 1990).

A adolescência provoca mudanças também na família extensa redefinindo os relacionamentos e exigindo mudanças estruturais e renegociação de papéis, em pelo menos três gerações. $\mathrm{O}$ movimento dialético de pertencimento e separação reatualiza as regras transgeracionais e os padrões de relacionamento dos diferentes sistemas familiares de origem, sendo que o movimento de autonomização dos filhos varia em função dos mitos familiares de cada um dos pais (Miermont et al., 1994; Preto, 1995). Este processo é descrito por Bowen (1991) sob a denominação de "transmissão multigeracional" e descreve a transmissão dos níveis de diferenciação do self da família, através das gerações múltiplas.

\section{Uma leitura sistêmica do envolvimento com atos infracionais e com drogas na adolescência}

A discussão sobre a contribuição da família na construção da identidade de seus filhos leva-nos a reflexão sobre os sintomas que podem aparecer, caso a família enfrente dificuldades nesse processo. Os sintomas que aparecem, nesta pesquisa, são o uso de drogas e o envolvimento com atos infracionais,

Para a abordagem sistêmica, o sintoma de um dos membros da família é compreendido como um fenômeno relacional, que tem uma função, no e para o sistema (Miermont et al.,1994), funcionando como regulador do sistema, tentando superar a crise, sem que nenhuma mudança real ocorra (Ausloos, 1977; Fishman, 1996; Samaniego \& Schürmann, 1999). Mas o sintoma, ao mesmo tempo que regula o sistema, também denuncia suas dificuldades em enfrentar crises específicas

Assim, o uso de drogas e o cometimento de atos infracionais passa a ser analisado como um sintoma de toda a família, sendo encarado como uma forma de lidar com os conflitos, mais do que um problema em si mesmo. A função desse sintoma é conduzir uma mensagem que denuncia falhas do 
sistema familiar e social, ao mesmo tempo que indica a necessidade de mudança no seu funcionamento (Bulaccio, 1992; Rosset, 2003; Roussaux, 1982; Sudbrack, 1992a).

A chegada da adolescência é um dos momentos propícios para que o uso de drogas surja como um dos sintomas que denuncia as dificuldades familiares em atravessar essa etapa do Ciclo de Vida Familiar, pois esse momento implica crescimento e individuação, movimentos essenciais na busca do jovem pela sua autonomia e independência do grupo familiar (Stanton \& Todd, 1988; Sudbrack, 2001, 2003).

A fantasia vivida pela família, principalmente pelos pais, de que estão perdendo o seu filho, quando este demonstra movimentos de saída do sistema familiar, gera um estado nomeado por (Stanton \& Todd, 1988) como "pânico parental". Não se trata apenas de uma reação comum de medo pelo desconhecimento do processo da adolescência ou de tristeza pela falta do filho permanentemente em casa. Mais do que isso, é um sentimento de pavor que não pode sequer ser nomeado, mas paira todo o tempo sobre o sistema familiar, ameaçando-o de destruição. Isto ocorre porque a possibilidade de crescimento e independência do filho é vista como uma ameaça à continuidade familiar. Assim, esse "pânico" confirma a impossibilidade da separação, vista como ruptura e abandono (Goubier-Boula \& Real, 1982), pois nessas famílias, não há a percepção de que os vínculos são permanentes, mas não são estáticos e que as pessoas co-evolue m em relação, num processo dialético entre autonomia e dependência (Colle, 2001).

O uso de drogas oferece a essas famílias uma solução paradoxal ao dilema criado sobre manter ou dissolver a família (Stanton et al., 1988). Esse filho, cuja tarefa é manter a estabilidade da família, encobrindo a realidade inaceitável da passagem do tempo, ao drogar-se, oferece a si mesmo em sacrifício pela manutenção do equilíbrio do sistema familiar (Castilho, 1994; Colle, 2001; Kalina, 1988). Segundo Kalina, Kovadloff, Roig, Serran e Cesarman (1999) "O filho que esteja destinado a não ser, ou seja, a não ter uma identidade própria, em seu afã por ser escolhe uma forma de não-ser, como é a identidade do drogadito" (p. 47). Essa solução, a despeito do sofrimento 
que traz para o adolescente e sua família, é bem vinda, pois a independência do filho é uma ameaça mais destrutiva para a família do que a dependência química (Mowatt, 1988).

O uso de drogas, assim, é um mecanismo substitutivo numa tentativa de equilíbrio que não está sendo possível de ser realizada dentro do sistema familiar, a respeito da autonomia do adolescente, resultando numa pseudo individuação (Ausloos, 1982b; Goubier-Boula \& Real, 1982; Stanton \& Todd, 1988). Em outras palavras, é uma tentativa inapropriada de um membro da família em negociar sua emancipação do sistema familiar, que resulta em ciclos repetitivos de partidas e retornos da casa dos pais (Silvestre, 1996).

De forma semelhante, Sudbrack (2003) coloca que o seu trabalho junto aos adolescentes e suas famílias tem revelado que o uso de drogas constitui uma tentativa de separação frustrada, vivida sob a forma de rupturas violentas, que resultam em reconciliações fusionais. Desse modo, ao contrário de favorecer um movimento de autonomia, o uso de drogas reforça as dependências relacionais, levando-nos a concluir que o sujeito é um dependente da sua família (Castilho, 1994). Os sistemas familiares dos dependentes químicos nos mostram que a co-dependência afetiva é um laço indestrutível e estável. As mudanças do Ciclo de Vida Familiar, que deveriam perturbar esses vínculos, parece ter como único efeito as oscilações, mas mantêm inalterável a homeostase do sistema (Colle, 2001).

Nessa situação, o adolescente está triangulado no conflito parental, superenvolvido com a mãe, numa relação descrita como quase incestuosa, configurada pela ausência de barreiras geracionais e confusão de papéis (Kaufman, 1985; Miermont et al., 1997; Prata, Felice \& Bruno, 1996). São também famílias nas quais se observa a presença de segredos e mentiras como um mecanismo de proteção, acobertamento e negação do comportamento do dependente (Krestan \& Bepko, 1994; Sudbrack, 2003).

$\mathrm{O}$ ato delinqüente, assim como o uso de drogas, também é interpretado como uma tentativa inadequada de assinalar de forma dramática que os problemas enfrentados pela família, nesse momento do Ciclo de Vida Familiar, não podem mais ser resolvidos pelas regras familiares habituais e que 
essas devem ser reajustadas (Chirol \& Segond, 1983). Nessas famílias regidas pela "lei do silêncio", em que os conflitos com relação às regras intrínsecas do seu funcionamento não podem ser explicitados pela via da linguagem, uma saída possível é o ato infracional. Esse tem, portanto, a função de comunicar as dificuldades vividas no interior da família, em um movimento de "agir fora o que não se pode falar dentro" (Sudbrack, 1992b, p. 33).

Para Segond (1992), o aparecimento da delinquiência na adolescência está relacionado às dificuldades específicas de comunicação e à características relacionais dentro da família, mais do que a aspectos individuais de personalidade ou a fatores estruturais, como divórcio, situações de famílias não casadas ou número de filhos. Segundo o autor, a comunicação pelo duplo vínculo clivado ou cindido tem sido observada com freqüência nas famílias por ele tratadas.

Fishman (1996) também apresenta algumas características que podem ser resumidas da seguinte forma: a autoridade parental encontra-se debilitada em função de um desacordo crônico entre os pais sobre a educação dos filhos, sendo que um deles está excessivamente envolvido com o filho delinqüente. A respeito da educação dos filhos, Leborgne (1997) descreve os pais como companheiros ou como cúmplices da delinquiência dos filhos. Nesses casos, os adolescentes são "adultificados" e conduzidos progressivamente a fazer valer sua "lei", dentro da família, e depois, no exterior dela.

Sudbrack (1987, 1992a), estudando famílias com transações delitogênicas na realidade francesa, observou a presença de uma forte dependência emocional entre mãe e filho, que os impedia de viver um sem o outro; associado a dificuldades do casal em constituírem-se e apresentarem-se enquanto unidade.

\section{Metodologia}

São sujeitos desta pesquisa: dez adolescentes do sexo masculino, com idades entre dezessete e dezoito anos e escolaridade entre $3^{\mathrm{a}}$ série do $1^{\mathrm{o}}$ grau 
a $1^{\circ}$ ano do $2^{\circ}$ grau, cumprindo medida sócio-educativa de semiliberdade, com história de uso de drogas; e suas famílias. A escolha destes adolescentes obedeceu a três critérios: 1) disponibilidade do adolescente em participar de pelo menos duas Entrevistas Clínicas de Pesquisa; 2) concordância desse adolescente de que sua família participasse da pesquisa; e 3) participação da família em, no mínimo, uma das duas Entrevistas de Avaliação Familiar Sistêmica. Todos estes adolescentes haviam sido encaminhados pelo Juiz da Vara de Infância e Juventude, para atendimento psicossocial, no Centro de Formação em Psicologia da Universidade Católica de Brasília, no qual estavam recebendo tal atendimento.

Foi utilizada a metodologia qualitativa de pesquisa-intervenção (Lévy, 2001). Numa proposta de aproximação e interpretação da realidade, foram pensados vários momentos para a pesquisa, em que fosse possível apreender a realidade complexa desses adolescentes: 1) junto aos adolescentes em medida sócio-educativa de semiliberdade (Observação participante em grupos de atendimento psicossocial e Entrevistas Clínicas de Pesquisa); 2) junto às famílias (observação participante em reuniões familiares e Entrevista de Avaliação Familiar Sistêmica, elaborada a partir do construção do Ciclo de Vida Familiar e da história transgeracional - Genograma); 3) junto às instituições (observação participante no CDS - Centro de Desenvolvimento Social e pesquisa documental dos processos na VIJ - Varal da Infância e Juventude). Todas as entrevistas foram gravadas e transcritas e para as atividades de Observação foi utilizado um diário de campo.

\section{Construções a partir da aproximação da realidade dos sujeitos}

A partir do enfoque da Epistemologia Qualitativa, numa postura de produção de um conhecimento construtivo-interpretativo. (González Rey 1997, 1999a, 2003), os diferentes momentos de apreensão da realidade foram analisados. Inicialmente, foram apontados indicadores numa leitura geral de todas as informações, obtidas nas entrevistas que foram transcritas e nas leituras do diário de campo. Esse procedimento foi naturalmente mos- 
trando, paulatinamente, os sentidos comuns entre eles e, desse modo, foram construídas Zonas de Sentido (González Rey, 1997), entre elas a que denominamos "filho parental" que discutimos neste artigo. Estas Zonas de Sentido foram construídas a partir da compreensão dos papéis desempenhados por esses adolescentes na dinâmica de suas famílias, ao bngo do Ciclo de Vida Familiar, levando em consideração as relações da tríade pai-mãe-filho. A identificação dos papéis desempenhados pelos adolescentes levaram-nos obrigatoriamente aos papéis de pai e mãe, marido e mulher já que, numa perspectiva sistêmica, os papéis familiares são interdependentes (Minuchin \& Fishman, 1990).

\section{O filho parental}

O processo interpretativo da realidade dos adolescentes e suas famílias, baseado nas leituras do diário de campo e das entrevistas, levou-nos a concluir que esses adolescentes desempenham diferentes papéis, ao lado da mãe, ao longo do Ciclo de Vida Familiar. Procurando observar como o desempenho desses papéis interfere na construção de sua identidade, ao mesmo tempo que os leva ao uso de drogas e/ou ao envolvimento com atos infracionais, como forma de saída para as possíveis dificuldades vividas na sua família com relação à construção de sua identidade, sintetizamos, da seguinte forma, esta Zona de sentido: esse adolescente desempenha diferentes papéis ao lado da mãe, no decorrer do Ciclo de Vida Familiar, ocupando espaços vazios da relação conjugal, mantendo-se numa relação de rivalidade e/ou de afastamento do pai. O desempenho e o investimento nesses papéis dificulta a identificação com seu pai e, também, o movimento de separaçãoindividuação desse adolescente de sua família, complicando o seu processo de construção identitária. Uma das vias de resolução para lidar com a angústia vivida e criar possibilidades de separação e de liberação desse lugar de filho parentalizado pode ser buscar outros contextos de construção identitária, dentre esses, o uso de drogas que o leva, quase que simultaneamente, ao envolvimento com atos infracionais. A seguir, discutiremos os diferentes 
aspectos desta zona de sentido, a partir dos indicadores encontrados, ilustrando esta nossa discussão com falas dos adolescentes e suas mães, extraídas das entrevistas, quando acharmos relevante, para uma melhor compreensão do leitor.

\subsection{Papéis do filho parental na família ao longo do Ciclo de Vida} Familiar e construção identitária

A parentalização ou parentificação temporária é um arranjo natural e legítimo nas famílias sem necessariamente acarretar prejuízos para o funcionamento do sistema familiar; constitui a base da identificação da criança com os pais, já que a criança não se identifica com os pais, mas sim, com a posição parental (Miermont et al., 1994; Minuchin, 1982; Simon, Stierlin \& Wynne, 1988). Para esses autores, as dificuldades nesse processo surgem quando essa parentalização deixa de ser temporária. Ou seja, quando os pais, não podendo assumir seu papel parental e seu lugar de orientação, controle e tomada de decisões, confiam essa posição ao filho de forma sistemática. Nesses casos, o trabalho clínico e as pesquisas têm demonstrado um grande número de consequiências destrutivas para o desenvolvimento da criança ou do adolescente, bem como para o seu processo de diferenciação e separação da família (Valleau, Bergner \& Horton, 1995).

Esse filho parental é colocado numa posição na qual é excluído do subsistema fraterno e elevado ao subsistema parental, assumindo prematuramente uma responsabilidade emocional considerável, que pode incluir os papéis de confidente, pacificador, ajudante e fonte primária de suporte e cuidado para os pais (Jones \& Wells, 1996; Minuchin \& Fishman, 1990; Stein, Riedel \& Rotheram-Borus, 1999; Valleau, Bergner \& Horton, 1995).

Como filho parental, o adolescente pode aproximar-se de um dos genitores, afastando-se do outro. Essa dinâmica de aproximação-afastamento assume a forma de um triângulo em que dois membros são excessivamente próximos e um terceiro é excessivamente distante (Aylmer,1995). 
Observamos, nesse estudo, que geralmente a aproximação acorre em relação à mãe com um gradual afastamento do pai, sendo que esse afastamento pode ocorrer quando o adolescente percebe que a mãe sofre na relação com o pai:

Quando eles começava, eles começava a discutir assim, sabe, aî meu pai discutia com a minha mãe, minha mãe ficava chorando aí eu fui tipo tomando uma raiva, sabe do meu pai. Aí eu fui tipo afastando dele assim, aí fui afastando até agora que tô afastado (adolescente).

Nessa posição de filho parental, muito próximo da mãe e afastado do pai, esse adolescente passará a assumir papéis e responsabilidades que originalmente deveriam pertencer aos membros do casal. Desse modo, ele se torna o "homem da casa", em substituição ao pai (Ausloos, 1982a).

O conceito de papéis familiares constitui-se como um dos aspectos principais, embora não seja o único, da Teoria Sistêmica, no que diz respeito ao estudo da identidade em razão da sua importância para o desenvolvimento dos processos de individuação e pertencimento grupal, e para a saúde emocional do sistema familiar (Féres-Carneiro, 1992). Assim identificamos, na exploração desta Zona de Sentido, alguns papéis desempenhados por esse adolescente, que discutimos a seguir.

O primeiro grupo diz respeito aos papéis desempenhados pelo adolescente junto à família como um todo: cuidador e educador dos irmãos e provedor e protetor da família.

Cuidar e educar os irmãos faz parte das responsabilidades que esse filho assume. No caso, esse filho tem um status - conjunto de papéis que uma pessoa desempenha - de educador, sem que esse seja o seu estatuto - conjunto de papéis que lhe são legitimamente atribuídos socialmente (Miermont et al., 1994). Desempenha papéis que caberiam ao pai, mas que, na indisponibilidade desse pai em desempenhá-los, são atribuídos ao filho: "O mais pequeno que desobedece a minha mãe, tem hora que eu tenho que dar uns corretivos nele" (adolescente). 
Além de cuidar e educar os irmãos, esse adolescente divide com a mãe o papel de provedor da família, já que, sendo muito sensível às dificuldades financeiras da família, sente-se na obrigação e na necessidade de procurar um trabalho para ajudá-la a sustentar a casa. Como encontrou Marques (2001) em sua pesquisa sobre trabalho infantil, são adolescentes que desde crianças viam-se como responsáveis financeiros naturais do grupo familiar, em razão da ausência do pai provedor. Assim, deixam de ser criança, que brinca e estuda, para ajudar a mãe, como fica óbvio na fala a seguir: "Então às vezes eu falava pra ele: não filho, deixa que eu me viro, vai estudar. Não mãe, quero ajudar a senhora... Ah! mãe deixa eu lhe ajudar, a gente tá precisando... O negócio dele é trabalhar até hoje" (Mãe).

Esse adolescente assume também o papel de protetor do grupo familiar, defendendo a segurança da família do próprio pai, como nos conta uma mãe orgulhosa:

... depois que o M. tava preso, ele (o pai) falou pra mim o seguinte: que quando o M. saísse que ele ia tomar o lote de mim. Ia tomar o lote de mim, aí eu falei pro M., aí o M. ligou lá pra casa da vó dele, disse oh, minha vó, você fala pro meu pai que eu tô aqui preso, mas ele não fica perto donde tá minha mãe não. Diz que ele que vai vender o lote não, que ele não tem direito no lote. (Mãe)

Os papéis identificados como compondo o status desse adolescente na família incluem, ainda, aqueles que denunciam claramente a sua triangulação na relação do casal, que denominamos de ajudante da mãe, defensor da mãe contra as agressões do pai e companheiro da mãe. Esses papéis compõem o segundo grupo, que apresentaremos a seguir. No seu papel de ajudante da mãe, um adolescente nos relata orgulhoso: "Eu sempre gostava de ajudar minha mãe, arrumava a casa, lavava a louça, esses negócios, desde que eu era muito pequeno. Quando ela chegava, a casa tava toda limpa” (adolescente).

O papel de defensor da mãe contra as agressões do pai, aparece também muito cedo no Ciclo de Vida Familiar, pois esse adolescente, além de precisar se auto defender de um pai violento, aprende que precisará defender a mãe, sob o risco de perdê-la, caso não o faça, já que o pai poderá chegar ao 
extremo de matá-la. Assim, o filho criança torna-se um adulto precoce e luta com esse pai pela manutenção da vida da mãe e da sua própria vida, num processo doloroso, mas sem outras saídas aparentes. Temos aqui uma criança que, ao invés de ser protegida e cuidada, precisa defender a si mesma e a mãe do pai alcoólatra e violento:

Eu tinha, acho, que 10 anos, minha mãe deu outra chance pra ele ainda (o pai). Aí ele foi bebeu, deu uma facada na minha mãe, na virilha. Minha mãe nem foi pro hospital, nem nada... porque se fosse tinha que dar queixa. Aí foi... eu fiquei injuriado, peguei um pau, comecei a bater nele mais minha irmã. Aí nóis conseguiu botar meu pai do lado de fora. (adolescente)

Esse adolescente também esteve sempre muito envolvido nos conflitos conjugais e muito incomodado com o desrespeito do pai com relação à sua mãe, no que diz respeito ao envolvimento com outras mulheres, bem demonstrado no relato de uma mãe:

O M. via ele dentro do carro com ela, ele chegava lá em casa, acho que o M. tinha uns 14 anos, mãe, meu pai, eu vi meu pai com uma mulher lá dentro do carro lá. Eu digo não sei que que você vai ver com as mulher que ele anda. Ele dizia vamo lá mãe pra senhora ver, não, meu filho, eu não vou não. Ah! mamãe mas a senhora é besta demais. Não, eu não vou, M., deixa isso pra lá. O M. vinha me chamar pra ver o pai dele com a mulherada dentro do carro, bem lá pertinho da minha casa, entendeu? (Mãe)

O papel de companheiro da mãe, quase de marido, fica claro quando esse adolescente rivaliza com o namorado/marido da mãe pelo seu amor, sendo que a mãe não consegue se impor e demarcar as fronteiras geracionais, garantindo a esse filho o seu papel diferenciado na dinâmica familiar: "Quando ele tinha uns 7, 8 anos, eu arrumei um rapaz, gente! esse rapaz era tudo no mundo para mim. Ele diz (Referindo-se ao filho): eu vou comprar um revólver e vou te matar. O cara não me quer por causa dele. Ele não aceita" (Mãe). Ou quando as mães colocam que esse filho é o que mais gosta dela e o único que lhe faz carinho e companhia:

Apesar de tudo isso, ele parece que é o filho que gosta mais de mim, ele me beija, me abraça. Já os outros não faz isso. Ele sai: tiau mãe, me dá um beijo, mãe me 
leva na parada... ele assim é o mais dado mais comigo... ele é o mais amoroso comigo. (Mãe)

Desempenhar todos esses papéis impede esse adolescente de individuar-se e caminhar rumo à construção de uma identidade própria, já que enfrenta um terrível conflito entre seu status e seu estatuto.

O status de filho parental dificulta a existência de identificações estruturantes (Miermont et al., 1994), já que, nesse papel, o adolescente encontrase preso no vínculo envolvente, que é a relação mãe-filho, sem a possibilidade de entrada de um terceiro que garanta a separação da mãe e a identificação com o papel do pai. Paralelamente, compreendemos que o grau de comprometimento do filho com o pai depende muito da relação entre o pai e a mãe (Bowen, 1991).

Todas estas colocações mostram-nos a complexidade do processo identificatório do filho com o pai. Considerando que esse processo é fundamental para a formação da identidade e da personalidade (Corneau, 1989), esse adolescente encontrará dificuldades nesse processo, pois não se sente, ou não gostaria de se sentir, identificado ao pai. Sendo filho de um homem a quem considera como tão violento, vive um grande conflito sobre parecer ou não com esse pai. A solução aparentemente encontrada é negar qualquer semelhança e buscar, na família, outras pessoas com as quais possa se identificar. Isso fica evidente quando os sujeitos são interrogados a respeito de com quem na família se acham parecidos: "Eu acho que sou parecido com meu irmão mais velho, no jeito de ser e na aparência" (adolescente). "Eu me pareço com minha irmã' (adolescente).

Mas esse adolescente, embora com raiva e sofrimento, não está isento da identificação, mesmo que pelos aspectos negativos, com o pai. Assim, muitas vezes, tem comportamentos violentos como ele, num processo ambivalente de afastamento do pai pela negação e discordância em relação ao seu comportamento, e de aproximação, pela forma de agir semelhante:

Toda a vida foi nervoso. Fala, fala, fala, esmurra a mão na parede e sai quebrando tudo, do mesmo jeito que o pai, do mesmo jeitinho. É a mesma coisa do pai, acho que é genético, né? Eu tenho sofrido demais com esse menino. (Mãe) 
Mas essas identificações não parecem ser suficientes para permitir a esse adolescente a construção de um sentimento de identidade. Elas são parciais, como ele próprio: meio filho, meio irmão, meio companheiro. Como ressalta Minuchin (1982), são filhos sempre cortados ao meio, sem poder experimentar a sensação de ser, por inteiro, filhos. Carregam a dor de estarem presos ao triângulo pai-mãe-filho, emaranhados, superenvolvidos, preocupados em responder às exigências maternas, não existindo como pessoas reais, mas como personagens de um drama multigeracional (Aylmer, 1995; Calil, 1997). Pertencem a sistemas familiares em que as barreiras entre as gerações são frágeis e há uma confusão entre os papéis parentais, conjugais e filiais (Prata et al., 1996).

\subsection{Vivências dos pais em suas famílias de origem e o desempe-} nho dos papéis pareentais

Partindo do pressuposto de que um papel só pode ser definido em um sistema de oposição e complementariedade em relação com outros papéis e que todos os papéis familiares são interdependentes (Miermont, et al., 1994; Minuchin \& Fishman 1990; Simon et al., 1988), podemos concluir que os papéis desempenhados pelo filho parental denunciam dificuldades dos pais em desempenhar os seus papéis de pai e mãe.

"A parentalidade é um processo difícil, pois requer a capacidade de nutrir, guiar e controlar” (Minuchin, 1982, p. 62). A possibilidade de assumir papéis de pai e mãe está relacionada ao grau de satisfação das suas necessidades, nos papéis de filhos vividos nas suas famílias de origem, no âmbito da diferenciação do eu de cada um (Bowem, 1976, 1991; Castilho, 1994; Jones \& Wells, 1996; Simon et al., 1988).

Segundo Jones \& Wells (1996), os pais, muitas vezes, não possuem maturidade emocional porque não receberam os cuidados parentais na sua própria infância. Na construção dos genogramas, as mães desses adolescentes apresentam histórias familiares permeadas por muito sofrimento e abandono, nas quais não lhes foram assegurados papéis filiais adequados; outras mães relatam o sofrimento vivido pela falta dos pais. Algumas mães vive- 
ram esse processo de abandono e de falta paterna de forma tão dolorosa que se recusam a falar da história de suas famílias de origem, como demonstram as falas de diferentes mães:

Eu não gosto de falar do passado, sofri demais (Mãe). Meu pai foi embora quando eu tinha 2 anos, chamou minha mãe, ela disse que não ia deixar a família dela para acompanhar ele não. Eu não conheci pai nunca. Lembro que meu padrasto batia muito em mim (Mãe). Fui uma menina dedicada à vida mesmo, desde pequena. Eu não tive pai e comecei a trabalhar com 9 anos, eu sofria muito. (Mãe)

A não vivência dos papéis filiais parece impedir estas mães de se colocarem no papel de mães, permanecendo infantilizadas, buscando um lugar de filhas nessa nova família que formam, já que estão presas ao sofrimento vivido em suas famílias de origem. No sistema teórico proposto por Bowen (1991), tal situação pressupõe um apego emocional não resolvido a suas famílias de origem, levando a uma pouca indiferenciação do self. Sendo pouco diferenciadas não podem desempenhar papéis adultos, pois estão dominadas pela emoção, reagindo, quase sempre, de forma impulsiva e automática.

A descrição das famílias de origem dos pais, feita pelas mães, (apenas um pai foi entrevistado, já que os outros haviam morrido, desaparecidos, estavam afastados do filho pela separação do casal) também nos mostra que eles tiveram uma história carregada de sofrimento, na medida em que também foram privados da contribuição do seu próprio pai, na infância e adolescência. Isso parece impedir/dificultar a assunção do papel paterno. Cirillo, Berini e Mazza. (1997); e também, Cirillo, Rongone e Selvini (1998) sugerem que esses pais foram submetidos, de forma muito precoce, à coerção dos adultos e que tiveram um vínculo negativo com o seu próprio pai. Conhecer melhor a história dos pais desses adolescentes com seus pais, poderia nos fornecer informações sobre esse fato. Infelizmente isso não foi possível e o que temos são apenas os relatos das mães que, ao nos contar o que sabem das histórias dos pais, nos informam que: "O pai dele bebia muito. Também aprontava com mulheres e batia muito nos filhos” (Mãe)."O pai dele tinha várias amantes, tirava as coisas de dentro de casa para dar prás amantes" (Mãe). 
Esses depoimentos sugerem que os pais desses pais viviam sua vida sem se preocupar muito com os filhos, que provavelmente tiveram que assumir papéis adultos precocemente. Um estudo de Stein, Newcomb e Bentler (1993) mostra claramente esta relação transgeracional entre as dificuldades dos pais com seus filhos e as suas vivências com seus próprios pais, apontando principalmente para a presença do alcoolismo nos avós. Acreditamos que essas vivências, também presentes nesse estudo, contribuem para que os pais tenham dificuldade de serem pais e de nomearem seus filhos enquanto pertencentes à linhagem paterna. Nesse sentido, a agressividade ou a sua indiferença mascaram as dificuldades vividas nas famílias de origem, impedindo o estabelecimento de uma relação de intimidade e proximidade com os filhos.

Em função das dificuldades desses pais e mães em assumirem seus papéis junto aos filhos, estes criam imagens que os permitam no mear e lidar com a realidade que vivem junto à família. Aqui as mães são nomeadas pelos filhos como sofredoras, vítimas e trabalhadoras, necessitando do filho ao seu lado. Fazem, portanto, o complementar do seu papel de filhos parentalizados: "Minha mãe sempre trabalhou, lutou, nunca deixou faltar comida prá gente... me aproximei da minha mãe, porque percebia que ela sofria demais" (Homero). "Minha mãe tinha que trabalhar prá botar comida dentro de casa" (adolescente).

Os pais, por sua vez, são descritos num duplo papel ora violentos, ora indiferentes aos filhos e à esposa. Alguns adolescentes chegam a nomeá-los como "pai de botas", numa analogia à polícia, cuja função é interpretada como apenas punitiva. Esse "pai de botas" desperta inicialmente medo nos filhos. Mas, com o passar do tempo, esse medo vira revolta, que se expressa num desinteresse pelo pai: “....meu pai era um safado, nunca deu um centavo prá nóis, nóis já dormia com um pedaço de pau debaixo da cama com medo dele chegar e bater na gente. Prá mim, era só porrada. Eu não tenho pai... hoje, eu não quero nem saber dele, não. Eu não sinto falta do meu pai de jeito nenhum" (adolescente). "O M. podia tá fazendo o que fosse, se visse o pai chegando, ficava quieto ou se escondia no banheiro. Tinha muito medo dele, o M. tinha" (Mãe). 
5.3. O envolvimento em atos infracionais e com drogas: saídas para a angústia vivida no lugar de filho parental

A modificação no papel de um dos membros da família implica a transformação dos papéis complementares assumidos pelos outros. Esse movimento caracteriza o processo de crescimento do indivíduo e a contínua reorganização do sistema familiar, no decorrer do Ciclo de Vida Familiar. Pode acontecer que as regras do grupo neguem a autonomia dos membros e interditem a individuação. Nesse caso, cada membro está condenado a se comportar sempre da forma que o sistema impõe (Miermont et al., 1994).

Nesse estudo, observamos que o adolescente está impossibilitado de sair da posição de filho parental e caminhar rumo à construção de sua identidade, encontrando-se preso numa situação frente à qual não encontra formas de reagir. Acreditamos que a droga surge como uma solução para a angústia vivida nesse processo, como afirma Bullacio (1992). A ela é atribuído o poder de ajudar o adolescente a lidar com seus sentimentos, ou a relacionar-se como as pessoas. Do mesmo modo, o uso de drogas garante a possibilidade de vivência de outros papéis além daqueles do filho parental, propiciando a sensação de pertencimento e afiliação a outros contextos, garantindo formas de inclusão social:

"Quando venho aqui que eu não posso fumar, aí eu chego aqui é fico calado... aí quando eu fumo eu venho prá cá, aí eu já falo alguma coisa, não é muito, mas eu já falo mais. Quando vou a festas eu fumo para conversar. Todo mundo fuma” ( $a$ dolescente). "Não sei se eu vou parar de usar maconha, eu gosto, ela me deixa relax. Eu converso mais". (adolescente)

A impossibilidade de separação da família, mais especificamente da mãe, com quem tem uma relação de proximidade intensa, também justifica o uso de drogas por esses adolescentes, já que a saída de casa é considerada como uma ameaça de ruptura com a família, principalmente com a mãe (Goubier-Boula \& Real, 1982). Nesse caso, o ato de drogar-se permite “(...) abstrair momentaneamente da família, ficar sem ficar. Isto preserva o sentimento de lealdade familiar" (Stanton \& Todd, 1982, p. 287). Silvestre 
(1996) também afirma que o uso de drogas é uma tentativa inapropriada de um membro da família para negociar sua emancipação do sistema familiar. Assim podemos pensar que esse adolescente parentalizado, preso no paradoxo entre o sofrimento de deixar a mãe e a dificuldade de continuar convivendo com ela, recorre à droga como uma saída:

Ela começou a gritar comigo, a discutir. Aí eu fiz de conta que não tava nem ouvindo. Saí para a rua, quando eu fui ver, eu fui chegar na Semi às oito horas da noite e era para eu ter chegado lá oito da manhã. Drogado, todo sujo, porque eu caí. (adolescente)

Além disso, para esse adolescente, o uso de drogas possibilita uma aproximação e uma forma de identificação com o pai, num processo de delegação familiar de débitos transmitidos de geração em geração (Ausloos, 1982a). Todos os pais desse adolescentes tiveram ou tinham envolvimento com álcool. Sendo que alguns, além do álcool, também fizeram ou faziam uso de drogas. Estas informações confirmam os resultados apresentados nas pesquisas de Stanton e Todd (1982) em que cerca de $80 \%$ das famílias estudadas apresentavam um dependente nas gerações precedentes, seja de álcool, drogas ou TV. Além disso, a construção dos genogramas nos mostrou que os pais desses pais (avós dos adolescentes) e muitos tios maternos e paternos também faziam uso regular de álcool.

No entanto, as histórias que esses adolescentes e suas famílias contam-nos, mostram que a possibilidade de aproximação concreta do pai pelo uso de drogas e álcool é ineficaz. Os pais, excluídos da vida familiar, colocados numa posição periférica, não são sequer informados do uso de drogas pelo filho. Continuam, como sempre estiveram: afastados e à margem dos problemas familiares, não sendo responsáveis pelo que acontece na família: "Meu pai não ficou sabendo da maconha não...até hoje ele não sabe de nada" (adolescente). "Meu pai não sabe de nada. Eu nem sei onde meu pai está. Ele é mendigo, não tem casa." (adolescente)

A identificação, por outro lado, pode ocorrer a partir da possibilidade de alguma semelhança com esse pai. Na impossibilidade de se definirem como parecidos com esse pai em outros aspectos, porque ele é visto como 
violento e agressivo com os filhos e a mãe, uma alternativa pode ser a aproximação pelo uso de drogas e álcool. Essa semelhança entre pai e filho marca a única via de identificação possível com o pai:

Ele é o seguinte, ele bebia muito, muito. Aí a bebida tomou conta do corpo dele. Ele ia no bar, bebia duas cervejas, um dreyer já tava bêbado, já tava doidão, já tava caindo. Eu não eu bebo pra ficar ligado. Mas se eu continuar bebendo, bebendo, bebendo, aí, na idade mais pra lá eu posso ficar assim também. (adolescente)

Na busca da droga, o adolescente quase simultaneamente envolve-se com o grupo de pares e com os atos infracionais, como uma forma de ter dinheiro, não só para a droga, mas também para suprir as suas necessidades básicas, considerando o contexto de exclusão social e de pobreza no qual está inserido: "Não dá pra resistir não. Vê assim todo mundo bebendo, assim, você quebrado assim, sem nenhum tostão no bolso, aí não dá pra resistir não" (adolescente)."Talvez a falt a de dinheiro... . Não roubava só pra comprar droga não. Pra comprar alguma roupa que eu gosto, alguma coisa que eu queria pra mim" (adolescente).

Além disso, a necessidade de prover o lar também leva esse adolescente a cometer roubos e furtos, mantendo-o na posição de filho parental. Nesse caso, a vivência do papel de companheiro da mãe e a necessidade de ter dinheiro para ajudá-la no sustento da casa leva o adolescente a cometer o primeiro delito e a prosseguir nesta trajetória, fazendo com que a prática de pequenos roubos torne-se natural para ele, adquirindo, como encontrou Sudbrack (1987), uma certa equivalência com o trabalho:

Aí chegou um dia, aí minha mãe chegou em casa e falou assim: tá faltando dinheiro pra pagar a conta de luz e telefone. Aí eu falei assim: não se preocupa não, que eu vou ali e volto mais tarde, eu vou arrumar dinheiro pra senhora. Aí eu peguei e saí mais os meninos, tô na esquina, aí eu só vejo os meninos falando: E aí vamo sair agora, já chegou a hora. Aí eu falei: então vamos. Aí fui, aí fizêmo o primeiro assalto. Fui, ganhei de boa. Rachei um montão de dinheiro. (adolescente) 


\section{Considerações finais}

Observa-se, neste estudo, as complexas interações entre relações familiares, construção identitária, uso de drogas e atos infracionais. Compreendemos que esse adolescente preso numa relação triangulada com seus pais, assumindo papéis parentais, preenchendo vazios na relação conjugal ou na família, precisa sair do contexto familiar, em busca de alívio para a angústia vivida nesse processo e de outras possibilidades de construção identitária. Nesta forma de compreensão, o uso de drogas e o cometimento de atos infracionais são, portanto, saídas encontradas por estes adolescentes para resolver o conflito entre separar e pertencer.

Sua busca leva-o às drogas, ao grupo de pares e ao ato infracional, pois o contexto social no qual está inserido não lhe oferece muitas outras oportunidades diferentes, ou seja, o meio em que vive não o ajuda a produzir os modos de inclusão dentro de projetos mais integradores na sociedade (Carreteiro, no prelo).

Compreendemos que a dinâmica familiar que denominamos de filho parental não é a única que pode estar presente em famílias de adolescentes que se envolvem em atos infracionais e com drogas. Outras formas de organização familiar também podem dificultar o processo de construção identitária de adolescentes, levando-os ao envolvimento com drogas e atos infracionais.

Além disso, o fato de nossa pesquisa centrar-se nas relações familiares, não significa que estamos desconsiderando os aspectos sociais, individuais e políticos que envolvem a relação do homem com as drogas e o ato infracional. Este foi apenas um recorte feito a partir da nossa experiência enquanto terapeutas de família. Concordamos com Vasconcelos (2002) para quem a realidade é complexa e inesgotável, sendo todo conhecimento uma construção intersubjetiva, não havendo leis definitivas sobre a realidade. 


\title{
Agradecimento:
}

\section{À Universidade Católica de Brasília pelo apoio financeiro, por meio do seu programa de incentivo à qualificação docente.}

Penso, M. A. \& Sudbrack, M. F. O. (2004). Involvement in illegal acts and with drugs as possibilities to deal with the role of the parental child. Psicologia USP, 15(3), 29-54.

\begin{abstract}
This study intends to comprehend the contribution of family dynamics to the construction of identity in adolescents who have committed illegal acts and are drug addicts living in a situation of poverty and social exclusion. Its approach is based on the Systemic Theory. The qualitative methodology of research-intervention is used with ten adolescents under social-educative committals of semi-liberty and also with their families. The results point out the use of drugs and the practice of illegal acts in adolescence as a means to deal with the role of the parental child, permitting the resolution of the identity crisis.
\end{abstract}

Index terms: Family. Adolescence. Drug usage. Identity crisis.

Penso, M. A., \& Sudbrack, M. F. O. La délinquance et la toxicomanie chez les adolescents comme possibilité de jouer le role de fils parentalisé. Psicologia USP, 15(3), 29-54.

Résumé: Cette étude cherche à comprendre la contribution de la dynamique familiale dans le processus de construction identitaire chez les adolescents qui, à la fois, ont commis des infractions, font usage de drogues et vivent dans le contexte de pauvreté et d'exclusion sociale. Il s'agit des résultats partiels d'une "recherche action" (Thèse de Doctorat en Psychologie à 1'Université de Brasília, soutenue par le premier auteur sous la direction du deuxième) dans l`approche théorique de la thérapie familiale systémique. Les sujets de la recherche ont été dix adolescents sous mesure judiciaire de semi-liberté et leurs familles. Les résultats de la recherche 


\section{Maria Aparecida Penso e Maria Fátima Sudbrack}

montrent à quel point les pratiques délinquantes chez les jeunes, aussi bien que l'usage de drogues, sont des symptômes dont la signification à le sens d'un comportement de passage à l'acte qui nous revèle le rôle de sujets au sein de leurs familles. Les adolescents apparaissent donc comme des enfants parentalisés, trouvant dans ce rôle un chemin de solution pour leurs crises identitaires.

Mots-clés: Famille. Adolescence. Drogues. Identité.

\section{Referências}

Ausloos, G. (1977). Adolescence, délinquence et famile. Annales de Vancresson, 14, 8087.

Ausloos, G. (1982a). Systémes-homéostase-equilibration. Thérapie Familiale, 2(3), 197-203.

Ausloos, G. (1982b). La therapie familiale dans l'alcoolisme et les autres toxicomanies: Breve revue de la litterature americaine. Thérapie Familiale,3(3), 235-256.

Ausloos, G. (1983). Délinquance et thérapie familiale: le double-lien scindé thérapeutique. Bulletin de Psychologie, 359(36), 217-223.

Aylmer, R. C. (1995). O lançamento do jovem adulto solteiro. In B. Carter \& M. Mcgoldrick (Orgs.), As mudanças no ciclo de vida familiar (M. A. V. Veronese, trad., 2a ed., pp. 206-222). Porto alegre: Artes Médicas. (Trabalho original publicado em 1989)

Bowen, M. (1976). Theory in the practice of psychotherapy. In P. J. Guerin (Org.), Family therapy: Theory and practice (pp. 42-90). New York: Gardner Press.

Bowen, M. (1991). De la familia al individuo (B. E. A. Lonnné, trad.). Buenos Aires: Paidos. (Trabalho original publicado em 1979)

Bulaccio, B. (1992). Família e a clínica da drogadição. Psicologia: Teoria e Pesquisa, 8(suplemento), 459-467.

Calil, V. L. L. (1997). Terapia familiar e de casal. São Paulo: Summus.

Carreteiro, T. C. (no prelo). Culture du trafic de drogue a Rio de Janeiro .

Carter, B., \& McGoldrick, M. (1995). A mudanças no ciclo de vida familiar: uma estrutura para a terapia familiar. In B. Carter \& M. McGoldrick (Orgs.), As 
mudanças no ciclo de vida familiar (M. A. V. Veronese, trad., 2a ed., pp. 7-29). Porto Alegre: Artes Médicas. (Trabalho original publicado em 1989)

Castilho, T. (1994). A droga. In T. Castilho (Org.), Temas em terapia familiar (pp. 116143). São Paulo: Plexus.

Chirol, C., \& Segond, P. (1983). Délinquance des jeunes, homeostase familiale et sociale. Bulletin de Psychologie, 359(32), 237-247.

Cirillo, S., Berrini, R., Cambiasco, G., \& Mazza, R. (1997). La famílle du toxicomane. Paris: ESF Éditeur.

Cirillo, S., Rangone, G., \& Selvini, M. (1998). L'adolescent antisocial: le sous-groupe de familles "réguliéres". Thérapie Familiale, 19(4), 323-334.

Colle, F. X. (2001). Toxicomanias, sistemas e famílias. (M. J. Pereira, trad.). Lisboa: Climepsi. (Trabalho original publicado em 1996)

Corneau, G. (1991). Pai ausente - filho carente. (L. Jahn, trad.). São Paulo: Brasiliense. (Trabalho original publicado em 1989)

Cuendet, C. L. (1991). Évaluation de 18 adolescents et de leurs parents deux ans aprés la fin de l'intervention psichothérapique. Thérapie Familiale, 12(3), 257-271.

Féres-Carneiro, T. (1992). Família e saúde mental. Psicologia: Teoria e Pesquisa, 8(Suplemento), 485-494.

Fishman, H. C. (1996). Tratando adolescentes com problemas: uma abordagem da terapia familiar. (M. A. V. Veronese, trad.). Porto Alegre: Artes Médicas. (Trabalho original publicado em 1988)

González Rey, F. (1997). Epistemología cualitativa y subjetividad. São Paulo: EDUC.

González Rey, F. (1999a). La investigacion cualitativa en psicología: rumbos y desafíos. São Paulo: EDUC.

González Rey, F. (2003). Sujeito e subjetividade: uma aproximação histórico-cultural. (R. S. 1. Guzzo, trad.). São Paulo: Pioneira Thomson Learning.

Goubier-Boula, M. O., \& Real, O. (1982). L'incest, la mort e la toxicomanie: approche systémique. Thérapie Familiale, 3(3), 271-284.

Jones, R. A., \& Wells, M. (1996). An empirical study of parentification and personality. The American Journal of Family Therapy, 24(2), 145-152.

Kalina, E. (1988). Adolescencia y drogadicción. Buenos Aires: Nueva Visión.

Kalina, E., Kovadloff, S., Roig, P. M., Serran, J. C., \& Cersaman, F. (1999). Drogadição hoje. Porto Alegre: Artes Médicas. 


\section{Maria Aparecida Penso e Maria Fátima Sudbrack}

Kaufman, M. D. (1985). Substance abuse and family therapy. New York: Psychological Corporation Harcourt Brace Jovanovich.

Krestan, J., \& Bepko, C. (1994). Mentiras, segredos e silêncio: os múltiplos níveis da negação em famí lias aditivas. In E. Imber-Black (Org.), Os segredos na família e na terapia familiar (D. Batista, trad., pp. 147-165). Porto Alegre: Artes Médicas. (Trabalho original publicado em 1993)

Leborgne, A. (1997). Guidance sur mandat judiciare et délinquance. Thérapie familiale, 18(2), pp. 181-204.

Lévy, A. (2001). Ciências clínicas e organizações sociais (E. D. Galery, M. E. A. T. Lima \& N. M. de Franc, trads.). Belo Horizonte: Autêntica. (Trabalho original publicado em 1997)

Marques, V. U. (2001). Infâncias (pre)ocupadas: trabalho infantil, família e identidade. Brasília: Plano.

Miermont, J. (1994). Dicionário de terapias familiares: teoria e prática (C. Arturo Molina-Loza, trad.). Porto Alegre: Artes Médicas. (Trabalho original publicado em 1987)

Minuchin, S. (1982). Famílias: funcionamento e tratamento (J. A. Cunha, trad.). Porto Alegre: Artes Médicas. (Trabalho original publicado em 1980)

Minuchin, S., \& Fishman, H. C. (1990). Técnicas de terapia familiar (C. Kinsch \& M. E. F. R. Maia, trads.). Porto Alegre: Artes Médicas.

Mowatt, D. T. (1988). Uso del contacto inicial para evaluar el sistema familiar. In M. D. Stanton \& T. C. Todd (Orgs.), Terapia familiar del abuso y adiccion a las droga. (C. Gardini, trad., pp. 25-42). Buenos Aires: Gedisa. (Trabalho original publicado em 1985)

Prata, L., Felice, M., \& Bruno, S. (1996). Families avec une droguée: analyse de leurs dynamiques selon une optique systémique. Thérapie Familiale, 17(1), 115-125.

Preto, N. G. (1995). Transformações do sistema familiar na adolescência. In B. Carter \& M. Mcgoldrick (Orgs.), As mudanças no ciclo de vida familiar (M. A. V. Veronese, trad., 2a ed., pp. 223-247). Porto Alegre: Artes Médicas. (Trabalho original publicado em 1989)

Rosset, M. S. (2003). Pais \& filhos: uma relação delicada. Curitiba: Sol.

Roussaux, J. P. (1982). Familles d'heroinomanes en thérapie. Thérapie Familiale, 3(3), $257-269$.

Samaniego, M., \& Schürmann, A. M. (1999). L' écoute des familles face à la menace de toxicodépendance de l'adolecent. Thérapie Familiale, 20(1), 39-49. 
Segond, P. (1992). Família e transgressão. Psicologia: Teoria e Pesquisa, 8(Suplemento), 447-457.

Silvestre, M. (1996). Thérapie familiale et toxicomanie. Thérapie Familiale, 12(4), $327-335$.

Simon, F. B., Stierlin, H., \& Wynne, L. C. (1988). Vocabulário de terapia familiar (B. López, trad.). Buenos Aires: Gedisa. (Trabalho original publicado em 1984)

Stanton, M. D., \& Todd, T. C. (1982). Compte-rendu: toxicomanie, alcoolisme et Thérapie Familiale. Thérapie Familiale, 3(3), 285-287.

Stanton, M. D., Todd T. C., Heard, D. B., Kirschner, S., Kleinman, J. I., Mowatt, D. T., Riley, P., Scott, S. M., \& Vandeusen, J. M. (1988). Um modelo conceitual. In M. D. Stanton, T. C. \& Todd (Orgs.), Terapia familiar del abuso y adiccion a las drogas (C. Gardini, trad., pp. 25-42). Buenos Aires: Gedisa. (Trabalho original publicado em 1985)

Stanton, M. D., \& Todd T. C. (1988). El modelo terapéutico. In M. D. Stanton \& T. C. Todd (Orgs.), Terapia familiar del abuso y adiccion a las drogas (C. Gardini, trad., pp 101-159). Buenos Aires: Gedisa. (Trabalho original publicado em 1985)

Stein, J. A., Newcomb, M. D., \& Bentler (1993). Differential effects of parent and grandparent drug use on behavior problems of male and female children. Developmental Psychology, 29(1), 31-43.

Stein, J. A., Riedel, M., \& Rotheram-Borus, M. J. (1999). Parentification and its impact on adolescent children of parents with AIDS. Family Process, 38(2), 193-208.

Sudbrack, M. F. O. (1987). La dimension familiale dans la delinquance des jeunes. Tese de Doutorado, Universitè du Paris -Nord, Paris.

Sudbrack, M. F. O. (1992a). Da falta do pai à busca da lei: o significado da passagem ao ato delinqüente no contexto familiar e institucional. Psicologia: Teoria e Pesquisa, 8 (Suplemento), 447-457.

Sudbrack, M. F. O. (1992b). Integrando psicologia social e da personalidade: reflexões a partir do paradigma eco-sistêmico e da epistemologia da complexidade. PSICO, 23(1) 49-67.

Sudbrack, M. F. O. (2001). A drogadição na perspectiva relacional e sua abordagem no contexto da saúde. In E. D. Alves, E. C. Araújo, \& S. F. Silva (Orgs.), Capacitação de instrutores para promoção da saúde em ações anti-drogas (pp. 71-86). Brasília, DF: SENAD.

Sudbrack, M. F. O. (2003). Terapia familiar e dependência de drogas: construções teórico-metodológicas no paradigma da Complexidade. In I. I. Costa, A. F. Holanda, F. C. Martins, \& M. I. Tafuri (Orgs.), Ética, linguagem e sofrimento. 
Anais, VI Conferência Internacional sobre Filosofia, Psiquiatria e Psicologia (pp. 273-293). Brasília: Positiva.

Valleau, M. P., Bergner, M. R., \& Horton, C. B. (1995). Parentification and caretaker syndrome: na empiral investigation. Family Therapy, 22(Suplemento), 157-164

Vasconcellos, M. J. E. de (2002). Pensamento sistêmico: o novo paradigma da ciência. Campinas, SP: Papirus.

Vieytes-Schmitt, C. (1991). L'adolescence - temps des passions. Thérapie Familiale, 12(2), 121-133.

Recebido em 08.09.2004

Aceito em 25.10.2004 